\title{
Revisiting the Phillips Curve: Visualization from a Multidimensional Graphical Perspective
}

\author{
Mario Arturo Ruiz Estrada', Su-Fei Yap², Noor Azina Binti Ismail²
}

\begin{abstract}
This article explores the possibility of visualizing the Phillips curve from a multidimensional perspective. We use a new multidimensional coordinate space, the mega-dynamic disks multivariable random coordinate space in vertical position, which visualizes the graphical behavior of the Phillips curve from a multidimensional point of view. We take A. W. Phillips's original paper published in Economica in 1958,"The Relation between Unemployment and the Rate of Change of Money Wage Rates in the United Kingdom, 1861-1957," as our main bibliographical reference. The same paper also serves as our main database for transforming the original Phillips curve into a multidimensional graphical form. In essence, our paper extends the significance of the Phillips curve beyond mere theory to serve as a practical instrument for solving economic problems.
\end{abstract}

KEY WORDS: Inflation, Unemployment, Phillips curve, Multidimensional coordinate spaces, Econographicology

JEL Classification: Y20

${ }^{1}$ Social Security Research Centre (SSRC) \& Centre of Poverty and Development Studies (CPDS), Faculty of Economics and Administration, University of Malaya, Malaysia; ${ }^{2}$ Faculty of Economics and Administration, University of Malaya, Malaysia

\section{Introduction}

A. W. Phillips's groundbreaking paper was published fifty-five years ago. Now, we are proposing a new graphical model to visualize its great contribution to economics. Therefore, the main inspiration for this paper is based on transforming the original Phillips curve into a multidimensional graphical format that $\underline{\square}$ will provide greater understanding about the relation-

Correspondence concerning this article should be addressed to: Mario Arturo Ruiz Estrada, Social Security Research Centre (SSRC) \& Centre of Poverty and Development Studies (CPDS), Faculty of Economics and Administration, University of Malaya, Kuala Lumpur 50603, Malaysia. T: (+60) 37967-3728. E-mail: marioruiz@um.edu.my ship between unemployment and the rate of change of money wage rates from a multidimensional perspective. Therefore, this paper aspires to compare graphically how the Phillips curve behaves from two-dimensional and multi-dimensional perspectives. Our main objective is to propose an alternative multidimensional graphical framework that can enhance our understanding of the complex and dynamic relationship between unemployment and the rate of change of money wage rates within the same graphical space at different periods of time. This paper is divided into six sections: (i) the evolution of graphical methods in economics; (ii) how multidimensional coordinate spaces work; (iii) the transformation of the Phillips curve into a multidimensional graphical form; (iv) an 
introduction to the mega-dynamic disks multivariable random coordinate space in the vertical position; (v) the construction of the Phillips curve in a multidimensional graphical form; and (vi) observations about the difference between the two-dimensional and multidimensional graphical models in the visualization of the Phillips curve.

\section{The Evolution of Graphical Methods in Economics}

Previous research shows a strong link between the introduction of graphical methods in economics and the development of theories, methods and techniques in statistics and mathematics. In the $18^{\text {th }}$ century, for example, several new graphical methods were developed as a result of contemporary advances in mathematics and statistics research. These graphical methods include line graphs of time series data, curve-fitting and interpolation, measurement of error as a deviation from a graphed line, graphical analysis of periodic variation, statistical mapping, bar charts and printed coordinate chapters (Cohn, Cohn, Balch, \& Bradley, 2004). Playfair (2005) introduced the application of graphical methods in economic analysis. Playfair constructed a wonderful collection of graphs at the end of the $18^{\text {th }}$ century, which placed him far ahead of other economists at the time in terms of visualizing economic data.

The development of graphical methods in economics can be classified into two distinct phases. The first phase is the basic graphical method, which features histograms and scatter-plots. All of these types of graphs are based on the visualization of a single variable (Y) through time $(\mathrm{X})$ in the first quadrant in the twodimensional Cartesian coordinate system (see Figure 1). The main objective of the basic graphical method in economics is to study the behavior of a single economic variable (e.g., exports, unemployment, inflation rate, etc.) within a time frame based on a time series. In fact, Playfair may be considered the pioneer of the basic graphical method. The second phase in the development of graphical methods for economics is the complex graphical method. In economics, the complex graphical method is distinguished by the use of threedimensional coordinate systems. According to Maas (2005), Jevons first explored the merits of the graphical method for political economy. This is a case of the use of the complex graphical method in economics, where the form of the graph gives an idea of the possible representation of functions describing the relationship between the $\mathrm{X}, \mathrm{Y}$, and $\mathrm{Z}$ variables that suggests a causal interpretation of the relationship between $\mathrm{X}, \mathrm{Y}$ and $\mathrm{Z}$. Additionally, the uses of the complex graphical method are based on the two and three-dimensional Cartesian plane, introduced in 1637 by Descartes (Wise, 2011), who made substantial contributions to economics. The two and three-dimensional coordinate spaces opened a new era in economic theory by enabling analysis of a complex and dynamic economic phenomenon based on the relationship between two or three variables. However, it is necessary also to mention the major contribution of Cournot (Mirowski, 1991). Cournot derived the first formula for the rule of supply and demand as a function of price in a two-dimensional view. He was also the first economist to draw supply and demand curves from a graphical view. In addition to Cournot and Jevons, other innovative economists that contributed to the analytical graph system in economics over time include Walras (in the field of general equilibrium) and Marshall (in the field of partial equilibrium) (Boland, 1981). In the 20th century, economists' use and application of the complex graphical method was often based on sophisticated graphical techniques introduced during the development of new economic modelling. In particular, economists started to deploy advanced geometry in constructing their graphs. In addition, two- and three-dimensional Cartesian coordinate systems were also a part of complex economics research (Cohn, Cohn, Balch, \& Bradley, 2001). High technology and sophisticated analytical machines such as the electronic calculator and the computer facilitated the rapid development of the complex graphical method. The development of analytical instruments in economics took place in two stages. The first stage, which took place in the 1950s and $1960 \mathrm{~s}$, involved non-sophisticated computational instruments such as electronic calculators to compute basic mathematical expressions. The second stage, the sophisticated computational instruments, began in the mid-1980s when computers with high speeds and large storage capacities using sophisticated software and applications were first introduced. The use of sophisticated software and applications enabled easy information management, the application of difficult simulations 



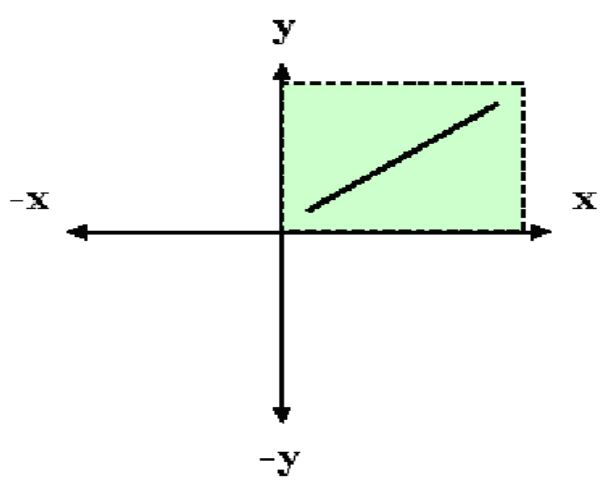

Figure 1. Two-Dimensional Coordinate Space

Source: Adapted from "Multi-dimensional coordinate spaces", by Ruiz Estrada (2011a) in International Journal of Physical Sciences, 6(3), 340-357.

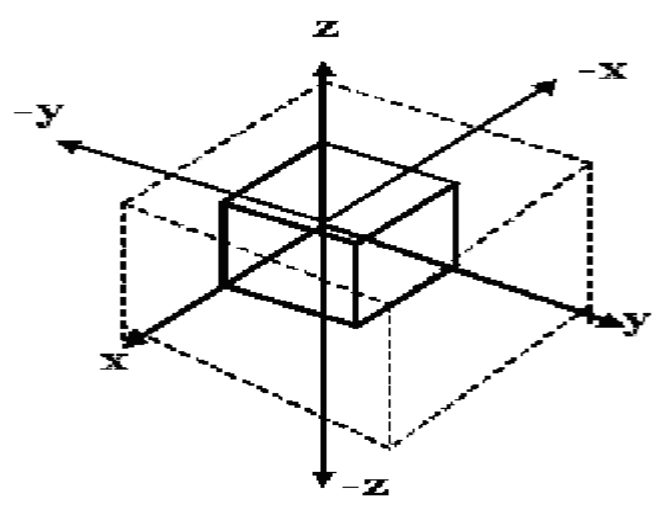

Figure 2. Three-Dimensional Coordinate Space

Source: Adapted from "Multi-dimensional coordinate spaces", by Ruiz Estrada (2011a) in International Journal of Physical Sciences, 6(3), 340-357.

in the same graphical space. These new types of multidimensional coordinate spaces are based on the mega-dynamic disks multivariable random coordinate space in vertical position. The multidimensional space enables economists, academics and policymakers to analyze economic phenomena from multidi- mensional perspectives across time and space. The proposed concept is preferred because it offers an immediate multidimensional perspective of the Phillips curve, thus presenting visually what normally would require a lot of data and substantial explanation. When the original Phillips curve was formulated 

ployment is low and to be low or negative when unemployment is high." This trend is observed in Figures 6 and 15. In fact, Phillips' main contribution is based on the argument that "There is also a clear tendency for the rate of change of money wage rates at any given level of unemployment to be above the average for that level of unemployment when unemployment is decreasing during the upswing of a trade cycle and to be below the average for that level of unemployment when unemployment is increasing during the downswing of a trade cycle." Moreover, the mathematical modeling that Phillips uses in his paper is based on a non-linear equation that is shown by equations $1,2,3$ and 4 .

$y=-a+b x$

$y+a=b x^{c}$

$\log (y+a)=\log b+c \log x$

$\log (y+a)=c \log b x$

According to Phillips (1958), the rate of change of wage rates is represented by " $y$ " and the percentage unemployment by " $\mathrm{x}$ ". The constants $\mathrm{b}$ and $\mathrm{c}$ were estimated by least squares using the values of $y$ and $\mathrm{x}$ corresponding to the crosses in the four intervals between 0 and 5 percent, respectively. The variable of unemployment that is a constant is chosen by random error to make the curve pass or be as close as possible to the remaining two crosses in two intervals between 5 and 11 percent, respectively. Finally, the equation of the fitted curve is represented by:

$y+0.900=9.638 x^{-1.394}$

$\log (y+0.900)=\log 9.638+\log x^{-1.394}$

$\log (y+0.900)=0.984-1.394 \log x$

Therefore, Phillips supports the construction of the fitted curve based on a simple multiple regression of $y$ on the variables $\mathrm{x}$ and the differentiation between $\mathrm{dx} / \mathrm{dt}$. He clearly described the difficulty of finding a suitable linear multiple regression equation to evaluate the relationship between unemployment and the rate of change of money wage rates. From a geometrical point of view, all of Phillips's visualizations presented a peculiar fitted curve together with a large series of plotted points representing the relationship between average rates of unemployment and the average rate of change of wage rates. In our opinion, many academicians confuse the fitted curve and try to show that if the unemployment rate is low, then the rate of change of wage rates is high. We can observe that the fitted curve moves from quadrant one $(+\mathrm{X},+\mathrm{Y})$ to quadrant four $(+\mathrm{X},-\mathrm{Y})$ in the two-dimensional Cartesian plane (see Figure 2). Hence, if the unemployment rate is equal to 5.5 , then the rate of change of wage rates is zero. The same fitted curve maintains the rate of change of wage rates trend between 10 and -3 in the case of the Y-axis. According to our observations, the unemployment range goes up to 11 for all figures in the same paper. Finally, Phillips assembles all of these points in a logical order around the fitted curve through the use of straight lines. In fact, we can observe that the visualization of all of these lines reveals chaos in the relationship between the unemployment and wages rates in the same graphical space and time. Therefore, Phillips' accuracy from the fitted curve demonstrates the relationship among these two variables. Therefore, we conclude that Phillips never used inflation, as many economists have assumed. In fact, the Phillips curve only shows the relationship between the change of wages and unemployment rate. He never applies inflation rates based on the CPI; rather, he tries to illustrate labor market behavior in certain periods of time according to his observations.

\subsection{Modern Approaches in the Construction of the Phillips Curve: The New Keynesian Phillips Curve (NKPC)}

The New Keynesian Phillips Curve (NKPC) is based on the relationship between marginal cost and the output gap. This new curve is based on two basic assumptions: (i) optimal price setting by monopolistically competitive firms; and (ii) constant frictionless markup $\mu$. According to the NKPC, the inflation dynamics are represented by equation 8 :

$\pi_{\mathrm{t}}=\beta \mathrm{E}_{\mathrm{t}}\left\{\pi_{\mathrm{t}+1}\right\}+\lambda f^{\prime} \mathrm{C}_{\mathrm{Tt}}$

Therefore, the marginal cost and the output gap are represented in equations 9 and 10 . 
$f^{\prime} \mathrm{C}_{\mathrm{Tt}}=(\sigma+\varphi) \mathrm{y}_{\mathrm{t}}$

The income gap is equal to:

$y_{t}=y_{t}-y_{t}$

We assume that everything produced is consumed in this model.

$y_{t=} C_{t}$

$\mathrm{K}=\lambda(\sigma+\varphi)$

Finally, the New Keynesian Phillips Curve (NKPC) is represented in equation 13 .

$\pi_{\mathrm{t}}=\beta \mathrm{E}_{\mathrm{t}}\left\{\pi_{\mathrm{t}+1}\right\}+\mathrm{K}_{\mathrm{t}}$

Accordingly, the New Keynesian Phillips Curve (NKPC) is consistent with rational expectations. The NKPC rests on three basic conditions: (i) inflation leads measure the output gap without trade-off between inflation and output gap stabilization; (ii) disinflation can be achieved without cost; and (iii) inflation is purely forward-looking, and past inflation is irrelevant. A number of studies utilize NKPC, such as Ball and Mazumder in "What Determines the Sacrifice Ratio?" (2011) and Fuhrer and Moore in "Inflation Persistence" (1995). Moreover, Friedman is a sharp critic of the ability to apply rational expectations with the NKPC (Lucas \& Sargent, 1981). According to Friedman (1968), “The Keynesian model implicitly relied on the idea that low unemployment could be sustained by allowing high inflation to erode real wages and thus boost labor demand. Friedman pointed out that if policy tried to keep output above its 'potential' or 'equilibrium' level, then wage-bargainers would get used to the higher level of inflation and adjust their nominal wage demands upwards. The result would be higher inflation without the sustainable low unemployment." Finally, Friedman (1968) mentioned that the traditional Phillips curve was an inadequate model for rational expectations because they are based on neoclassical micro-foundations such as sticky prices (without some type of rigid prices) for macroeconomic modeling. From a visual perspective, the NKPC continues to use a two-dimensional coordinate system, which does not permit us to depict completely the real behavior between inflation and unemployment together in the same graphical modeling. Therefore, the next section tries to propose a new multidimensional graphical modeling that it is based on mega-dynamic disks multivariable random coordinate space in vertical position.

\section{Mega-Dynamic Disks Multivariable Random Coordinate Space in Vertical Position}

This paper proposes a unique multidimensional coordinate space called the mega-dynamic disks multivariable random coordinate space in vertical position (Ruiz Estrada, 2014). The mega-dynamic disks multivariable random coordinate space in vertical position captures $\mathrm{n}$-dimensions in the same graphical space at the same time. Therefore, this new special coordinate space creates the possibility of visualizing a large number of endogenous and exogenous variables that are interconnected and moving in different graphical spaces with different time frameworks without any restriction. It facilitates the observation of how endogenous variables and exogenous variables work together simultaneously. At the same time, one can see how all of these variables interact together through the visualization of an asymmetric spiral-shaped figure with $\mathrm{n}$-faces that constantly moves in real time. This asymmetric spiralshaped figure with $\mathrm{n}$-faces can show an expansion or contraction that is based on different changes among all variables at different graphical spaces with different time frameworks.

Initially, the mega-dynamic disks multivariable random coordinate space in vertical position proposes a new graphical modeling to visualize a large amount of data. First, this specific coordinate space shows one single vertical straight axis that captures endogenous variable behavior. Hence, we plot our endogenous variables on this single vertical straight axis that is represented by $a$. Second, each exogenous variable in an analysis is represented by its specific sub-coordinate system such as $\beta_{<S S i: D j\rangle}$, where " $S S_{i}$ " represents the sub-space level in analysis, in this case either from sub-space level zero $\left(S S_{0}{ }^{\circ}\right)$ to sub-space level infinite $\left(S S_{360}{ }^{\circ}\right)$, and " $D_{j}$ " represents the disk level in analysis at the same quadrant of exogenous variables (in our case, from disk level $1=D_{1}$, disk level $2=D_{2}$, disk level $3=D_{3}, \ldots$, to disk level $D_{\infty}$ ). In fact, we as- 


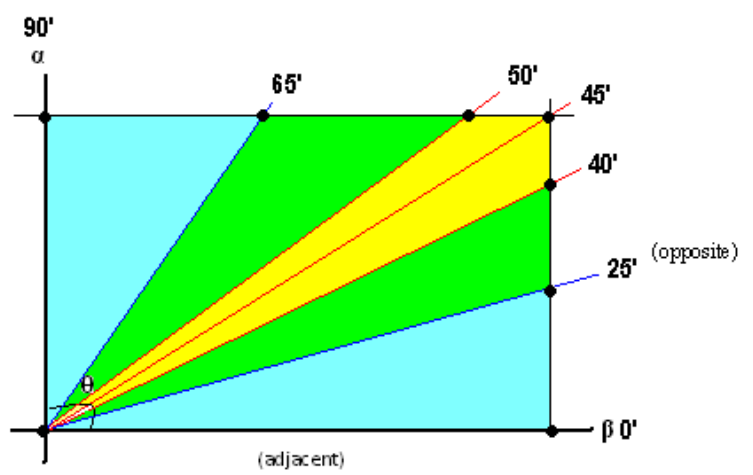

Representative Area between 50' \& 40'

Acceptable Area between 65'/51' \& 41'/25' $\square$

Non Representative area between $65^{\prime} 190^{\prime} \& 26^{\prime} 10^{\prime}$

Figure 3. $\tan (\beta / \alpha)^{-1}$
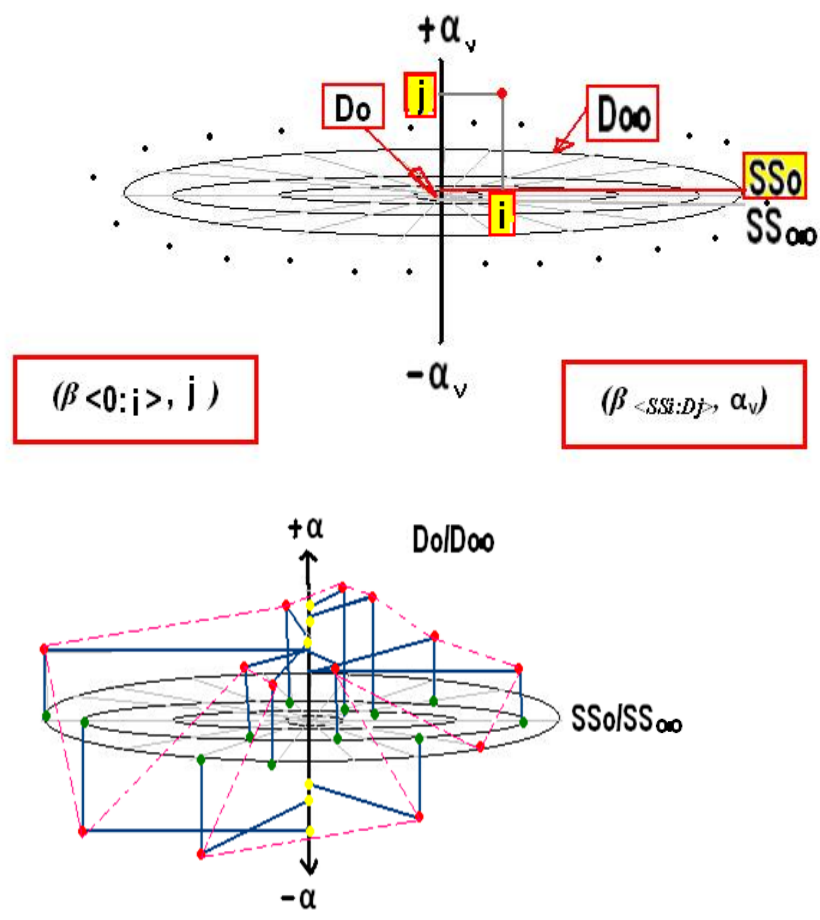

Figure 4. The Mega-Dynamic Disks Coordinate Space in Vertical Position

Source: Adapted from "An introduction to the mega-dynamic disks coordinate space in vertical and horizontal position", by Ruiz Estrada (2014) in Malaysian Journal of Sciences, 33(2), 105-109. 



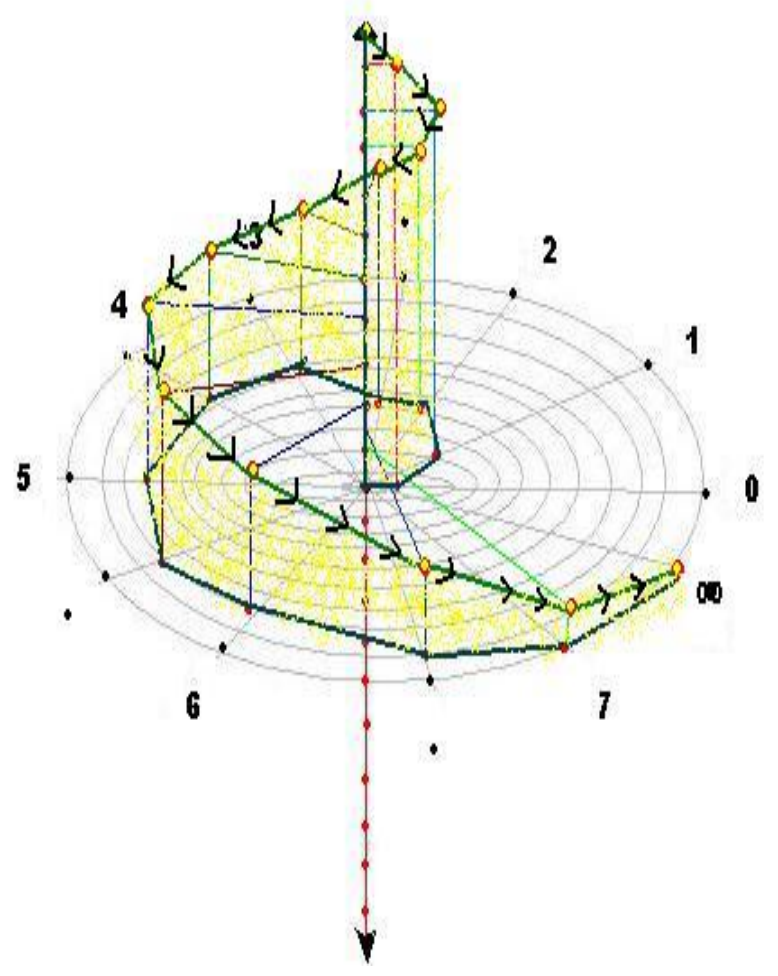

Figure 5. Relationship between the Average Rates of Change of Money \& Average Unemployment Source: Adapted from "The relation between unemployment and the rate of change of money wage rates in the United Kingdom, 1861-1957", by Philips (1958) in Economica, 25(100), 283-299.

a simple scatter diagram that shows a large amount of data (points) spread between the first and fourth quadrant in the two-dimensional Cartesian plane. In fact, the large amounts of points represent different groups of coordinates reflecting the relationship between unemployment rates and wage rates. According to Phillips (1958), "Each dot in the diagrams represents a year, the average rate of change of money wage rates during the year being given by the scale on the vertical axis and the average unemployment during the year by the scale on the horizontal axis."

Moreover, in Figure 5, we also observe a curve that is based on a logarithmic equation in Phillips' paper (1958, p. 290). Phillips tries to show graphically the re- lationship between the average rate of change of money wage rates during the year represented by the scale on the vertical axis (Y-axis or endogenous variable) and the average unemployment rate during the year represented on the horizontal axis (X-axis or exogenous variable). The unemployment rates can only be positive average rates. Hence, the unemployment average rates restriction is equal to $U=\left\{x \mid x: 0 \geq x \leq R_{+}\right\}$. The average rate of change of money wage rates has both positive and negative values. Therefore, the average rate of change of money wage rates restriction is equal to $\mathrm{W}=\left\{\mathrm{x} \mid \mathrm{x}: \mathbb{R}_{-} \leq \mathrm{x} \geq \mathbb{R}_{+}\right\}$. In Figure 5, we observe that Phillips plots 52 results showing the relationship between the average rate of change of money wage rates 


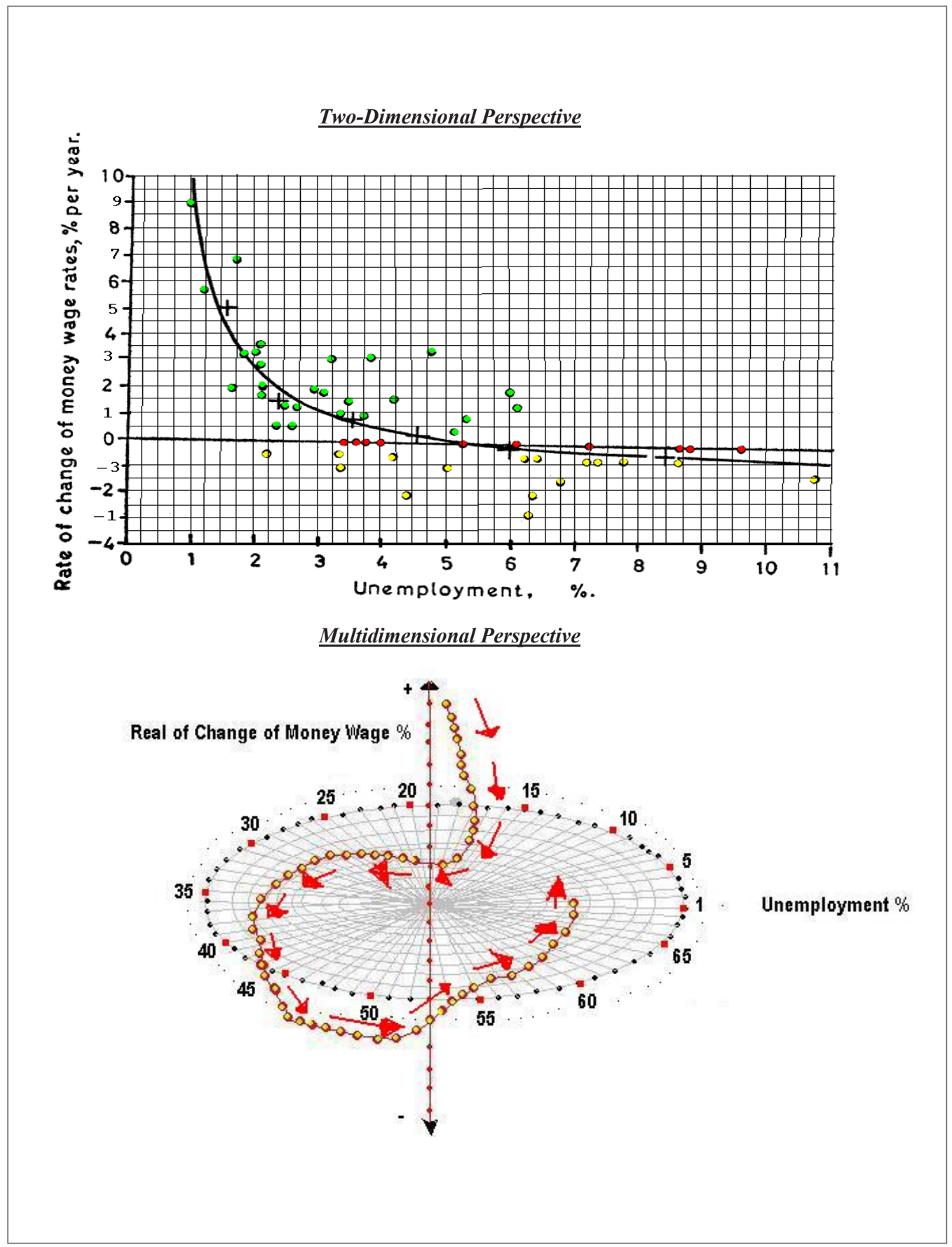

Figure 6. Relationship between the Average Rates of Change of Money \& Average Unemployment Source: Adapted from "The relation between unemployment and the rate of change of money wage rates in the United Kingdom, 1861-1957", by Philips (1958) in Economica, 25(100), 283-299. 


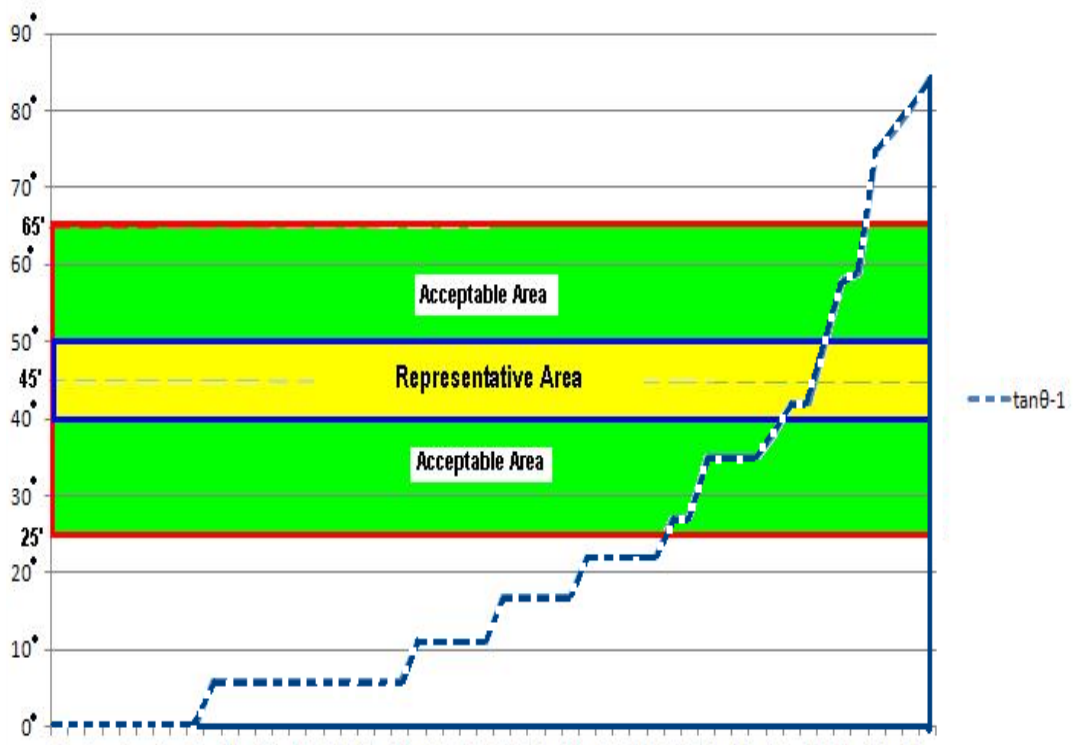

$\begin{array}{llllllllllllllllllllllllll}1 & 3 & 5 & 7 & 9 & 11 & 13 & 15 & 17 & 19 & 21 & 23 & 25 & 27 & 29 & 31 & 33 & 35 & 37 & 39 & 41 & 43 & 45 & 47 & 49 & 51\end{array}$

Figure 7. Multidimensional Phillips Curve Diagram

and the average unemployment rates from 1861 to 1913. Additionally, in Figure 6, we observe a perfect Phillips curve from a multidimensional perspective: when the average rate of change of money is high, there are low unemployment rates in the case of perfect competition. Hence, vertically higher positions (with higher money wage rates) are linked to the horizontal inner disk (lower unemployment).

\section{Observations about the Difference between the Two-Dimensional and Multidimensional Graphical Models in the Visualization of the Phillips Curve}

Figures $8,9,10,11,12,13,14,15,16$ and 17 present the visualization of the Phillips curve from a multidimensional perspective. Each set of figures in this paper shows the two-dimensional and multidimen- sional graphical models of the Phillips curve. Therefore, we clearly can appreciate the multidimensional graphical approach of the Phillips curve, which produces a multidimensional graphical optical effect compared to the two-dimensional perspective. Additionally, we can observe that the average rate of change of money wage rates and the average unemployment rates from 1861 to 1913 (see Figures 7, 8,9 and 14) have a stronger interconnectivity. The advantage of using the multidimensional graphical approach for the Phillips curve is based on the location of the coordinates that are displayed and follow a logical trajectory in different spaces and time within the same multidimensional coordinate space. Moreover, we can observe how the Phillips curve displayed in different spaces generates a floating effect in the same graphical space. According to Figures 10, 11, 12, 13 , and 14 , we can observe a non-linear spiral-shape 


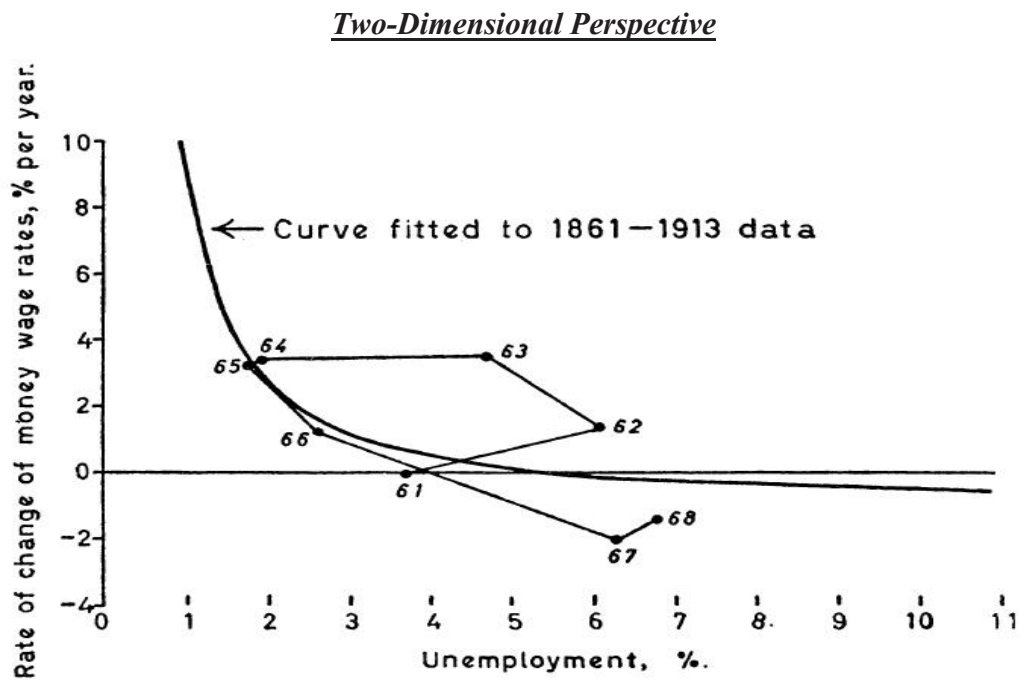

\section{Multidimensional Perspective}

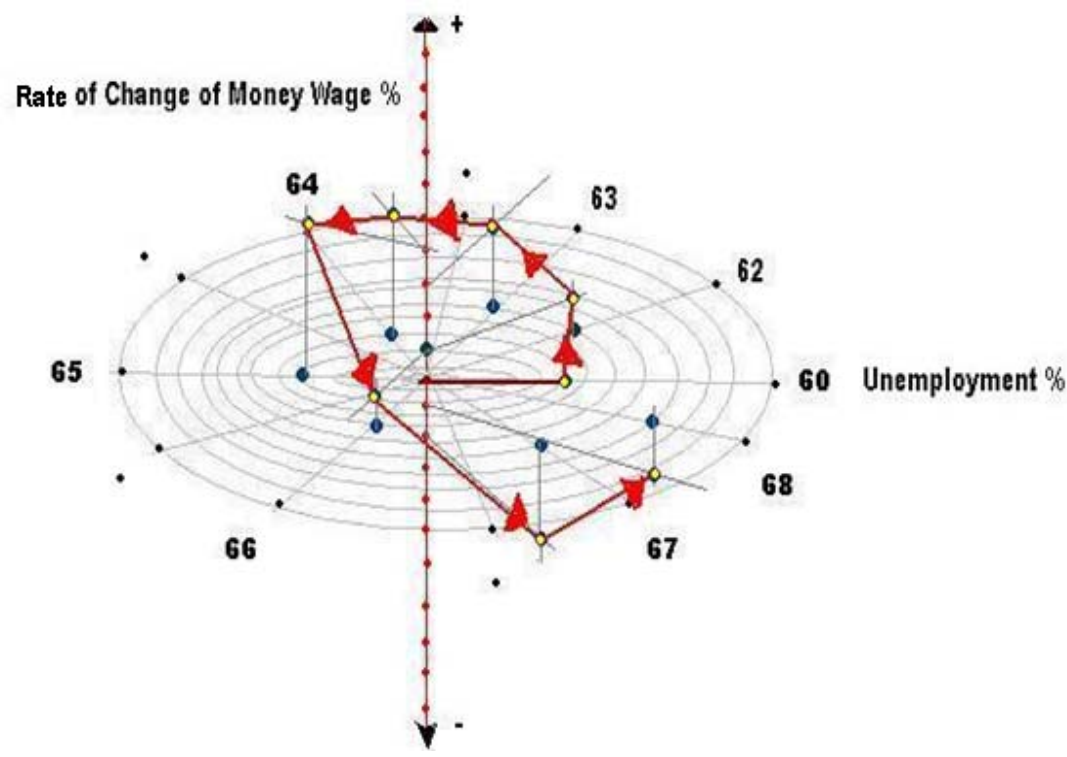

Figure 8. 1861-1913

Source: Adapted from "The relation between unemployment and the rate of change of money wage rates in the United Kingdom, 1861-1957", by Philips (1958) in Economica, 25(100), 283-299. 


\section{$\underline{\text { Two-Dimensional Perspective }}$}

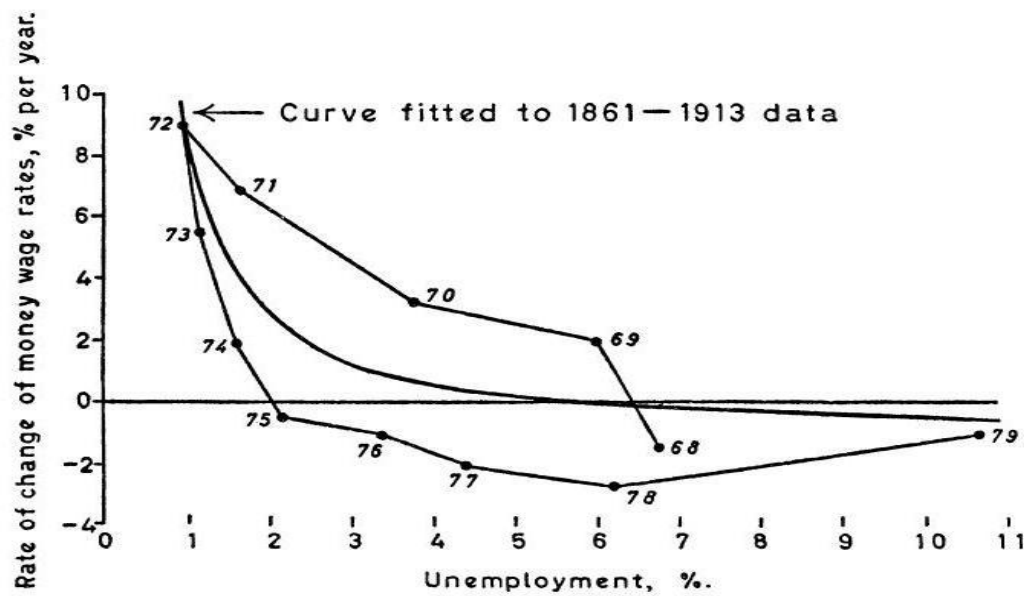

\section{Multidimensional Perspective}

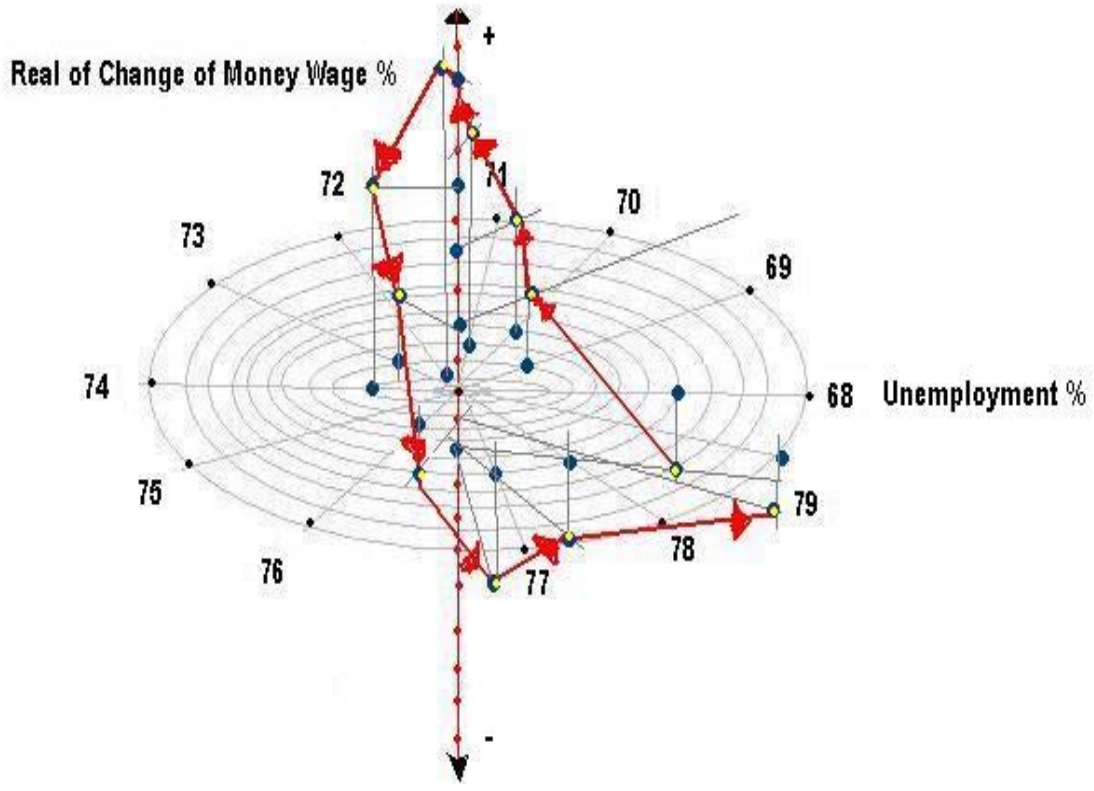

Figure 9. 1868-1879

Source: Adapted from "The relation between unemployment and the rate of change of money wage rates in the United Kingdom, 1861-1957", by Philips (1958) in Economica, 25(100), 283-299. 


\section{$\underline{\text { Two-Dimensional Perspective }}$}

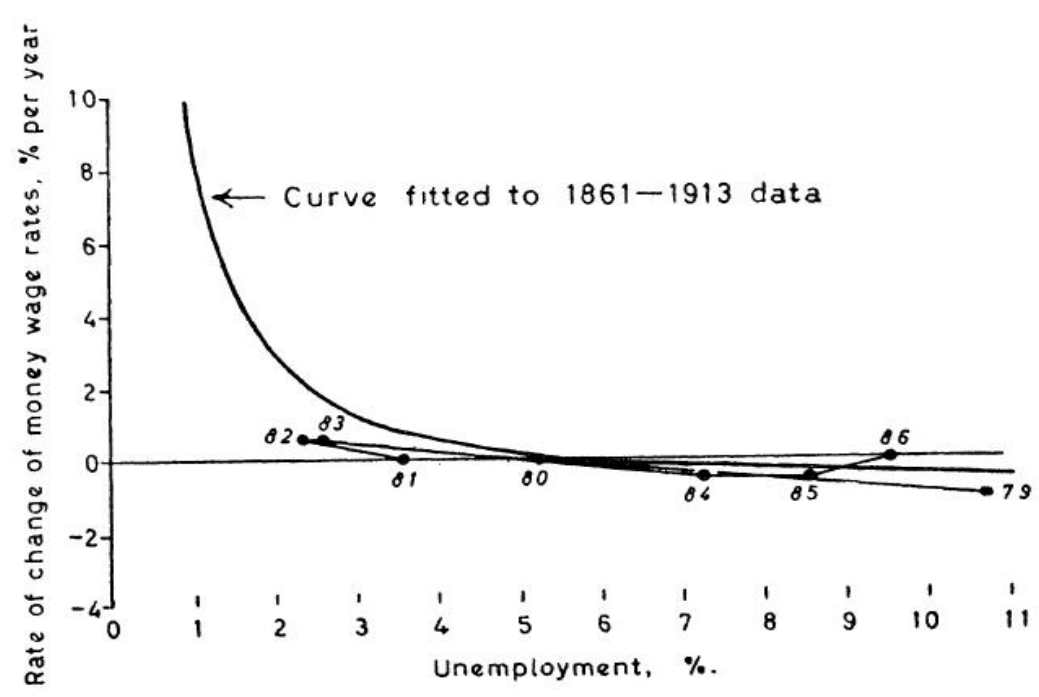

\section{Multidimensional Perspective}

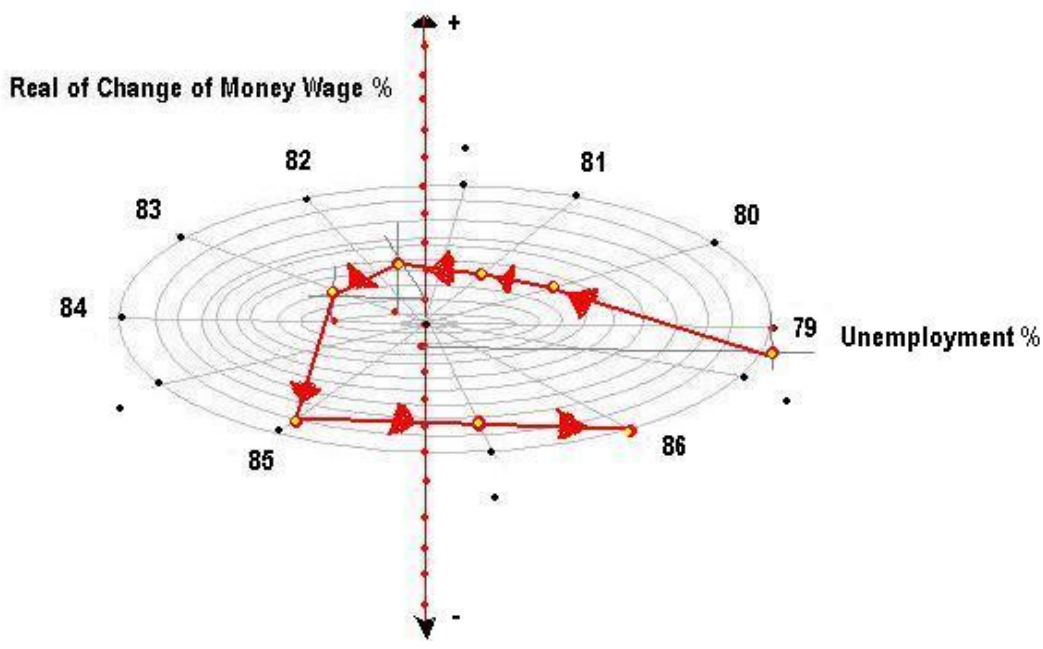

Figure 10. 1879-1886

Source: Adapted from "The relation between unemployment and the rate of change of money wage rates in the United Kingdom, 1861-1957", by Philips (1958) in Economica, 25(100), 283-299. 


\section{$\underline{\text { Two-Dimensional Perspective }}$}

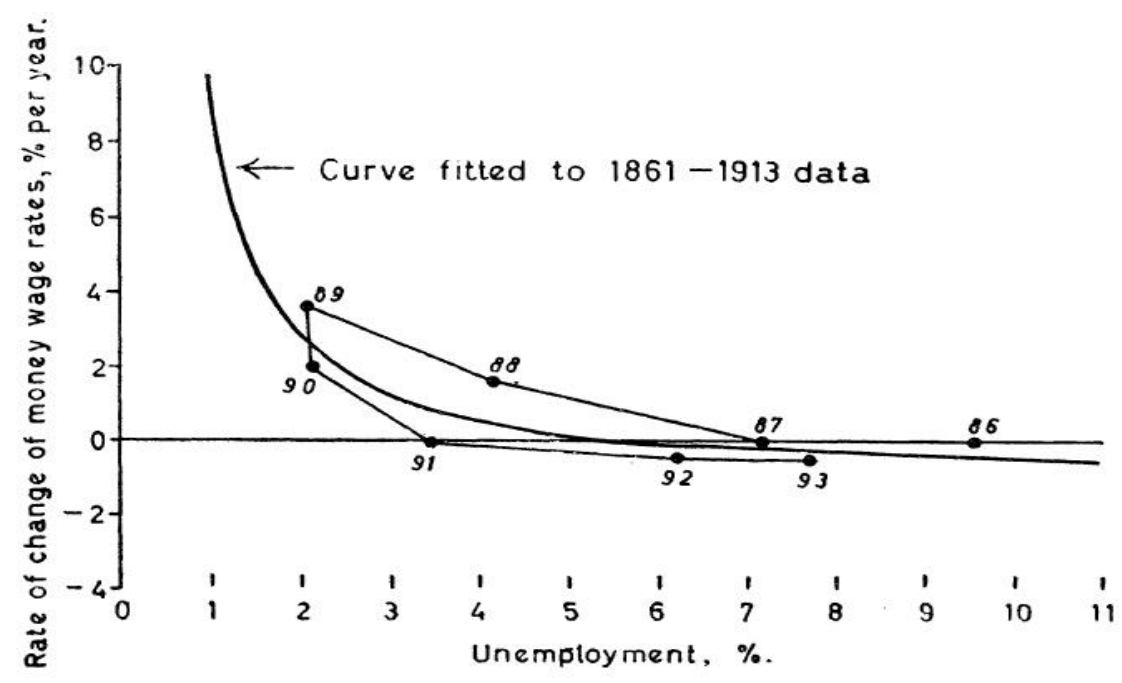

$\underline{\text { Multidimensional Perspective }}$

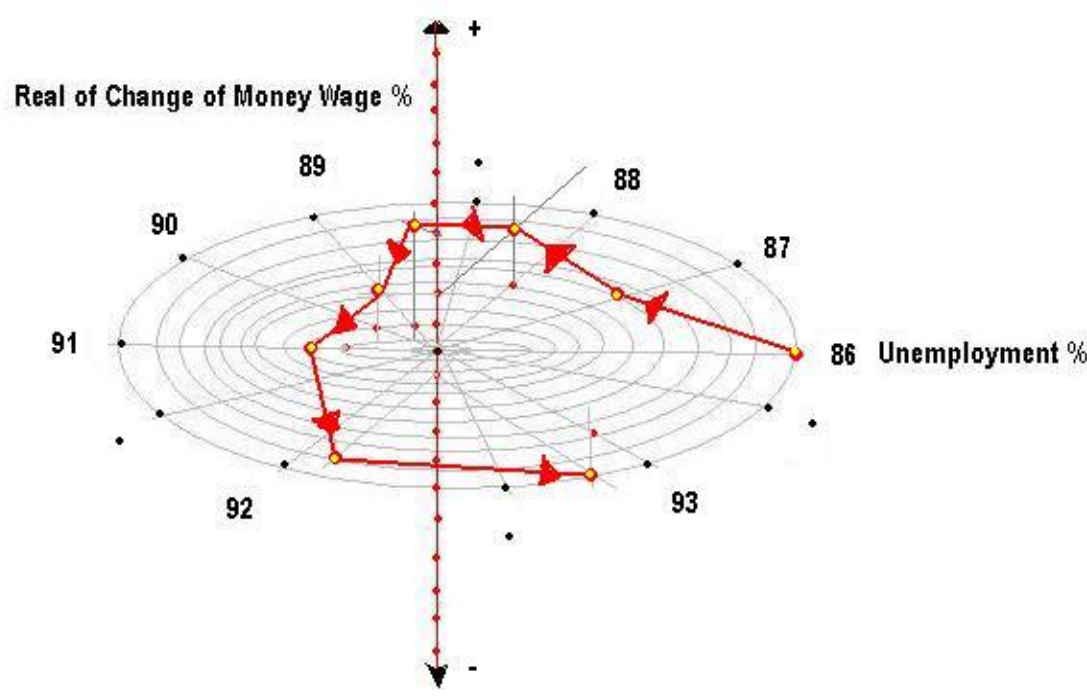

Figure 11. 1886-1893

Source: Adapted from "The relation between unemployment and the rate of change of money wage rates in the United Kingdom, 1861-1957", by Philips (1958) in Economica, 25(100), 283-299. 


\section{$\underline{\text { Two-Dimensional Perspective }}$}

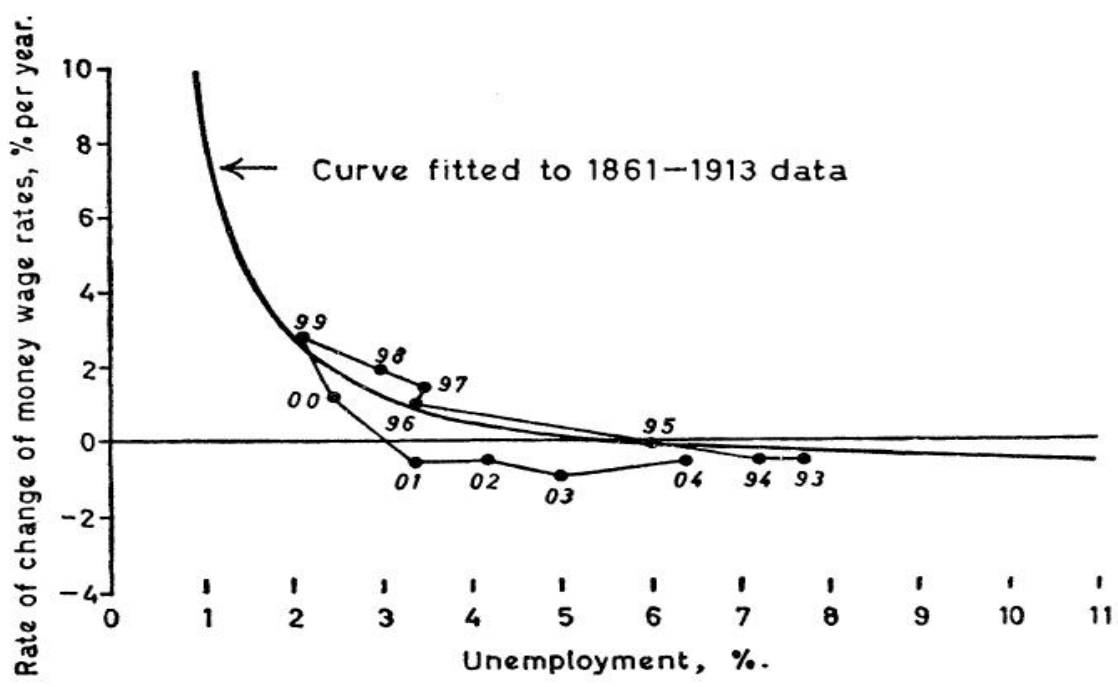

\section{Multidimensional Perspective}

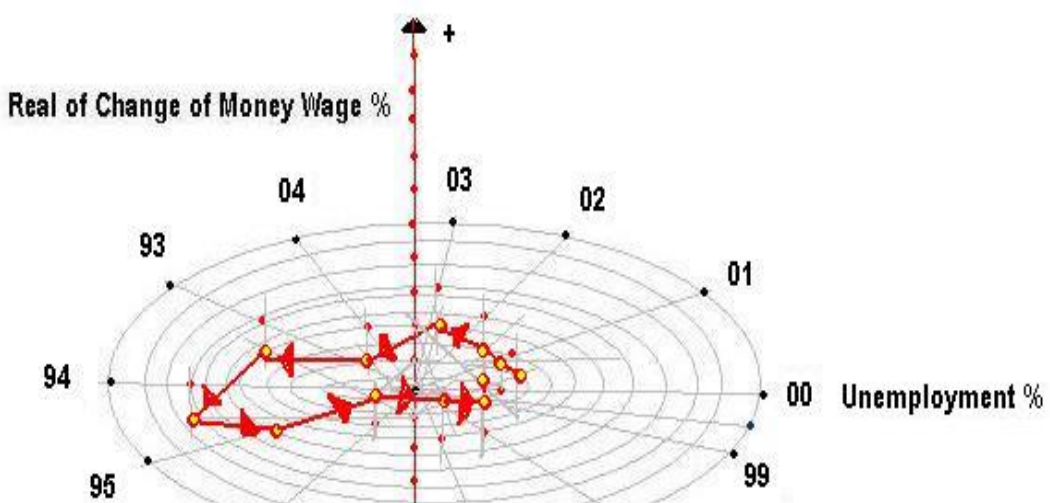

96

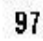

98

Figure 12. 1893-1904

Source: Adapted from "The relation between unemployment and the rate of change of money wage rates in the United Kingdom, 1861-1957", by Philips (1958) in Economica, 25(100), 283-299. 


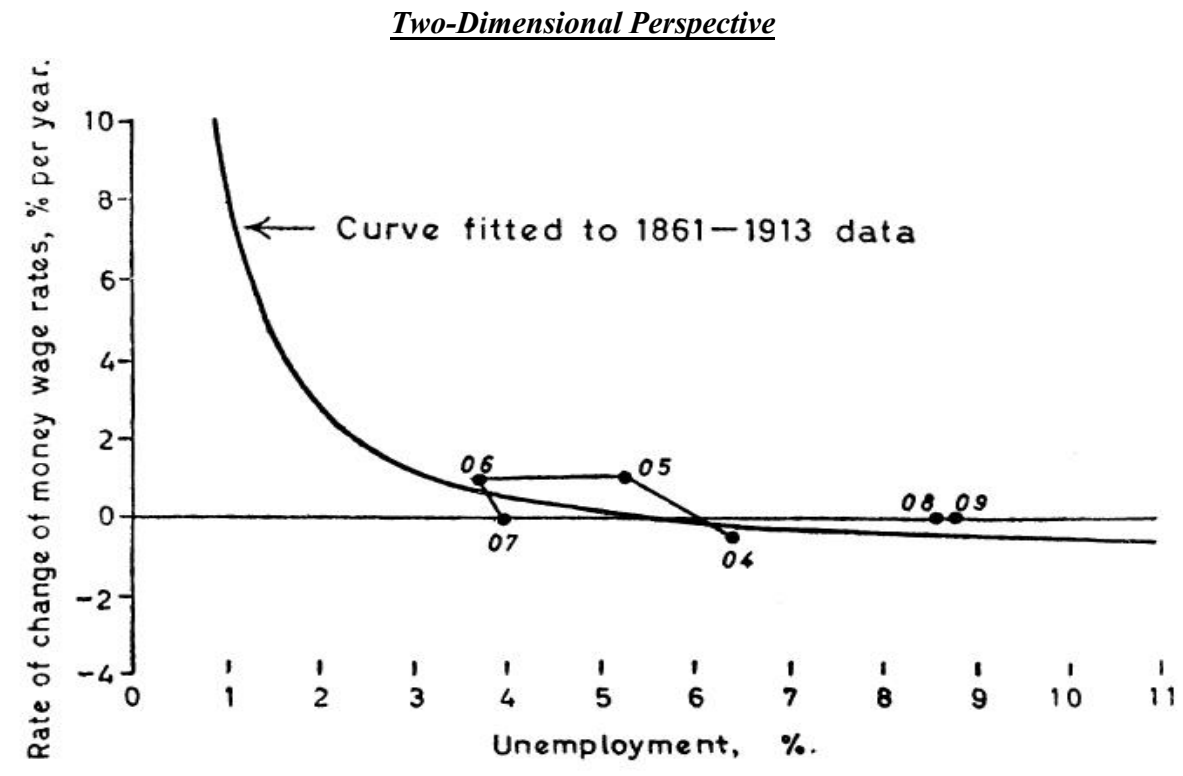

\section{Multidimensional Perspective}

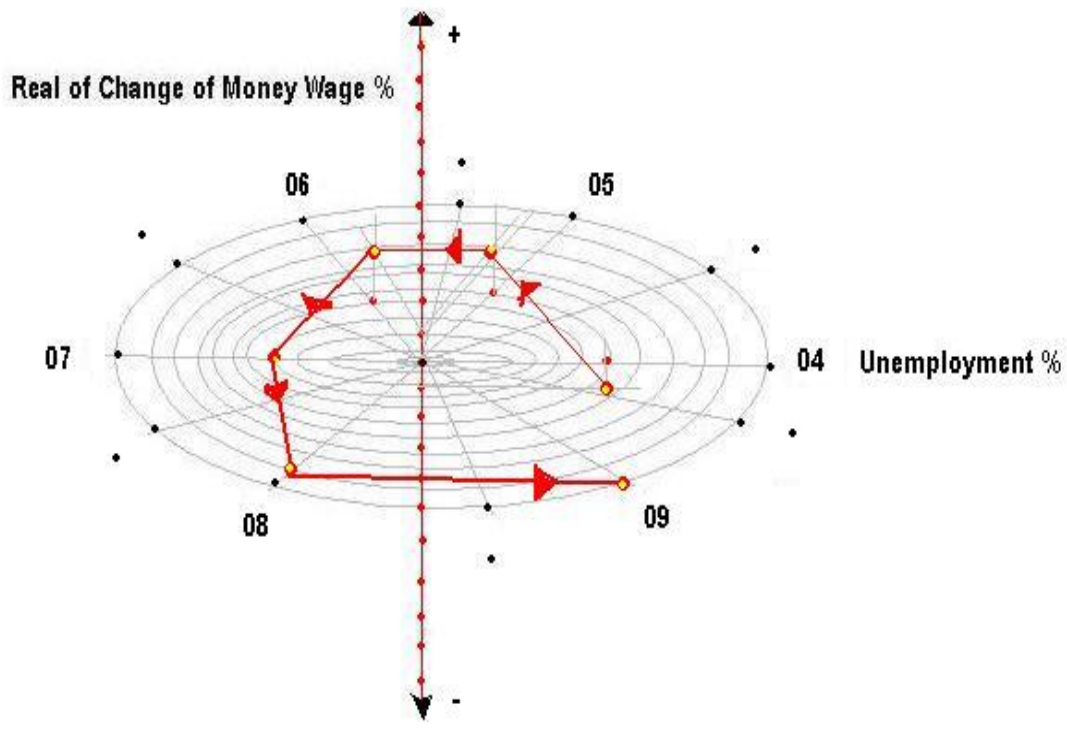

Figure 13. 1904-1909

Source: Adapted from "The relation between unemployment and the rate of change of money wage rates in the United Kingdom, 1861-1957", by Philips (1958) in Economica, 25(100), 283-299. 


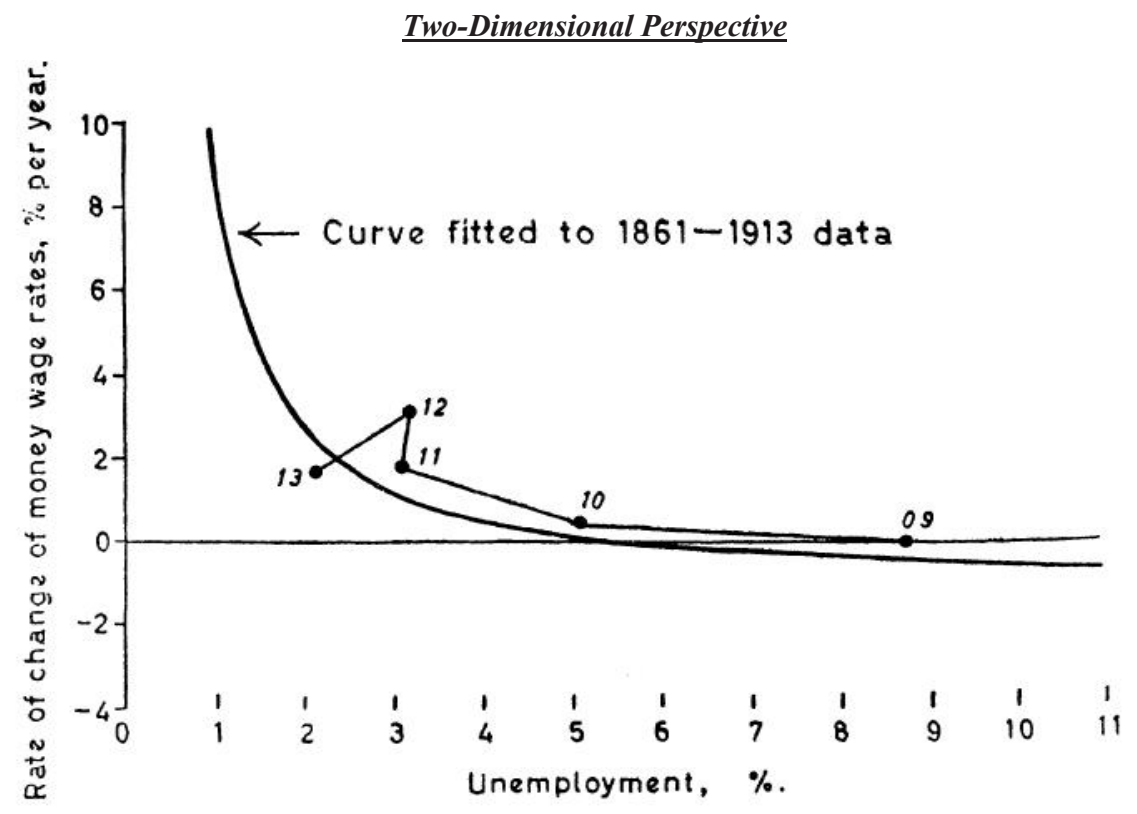

\section{$\underline{\text { Multidimensional Perspective }}$}

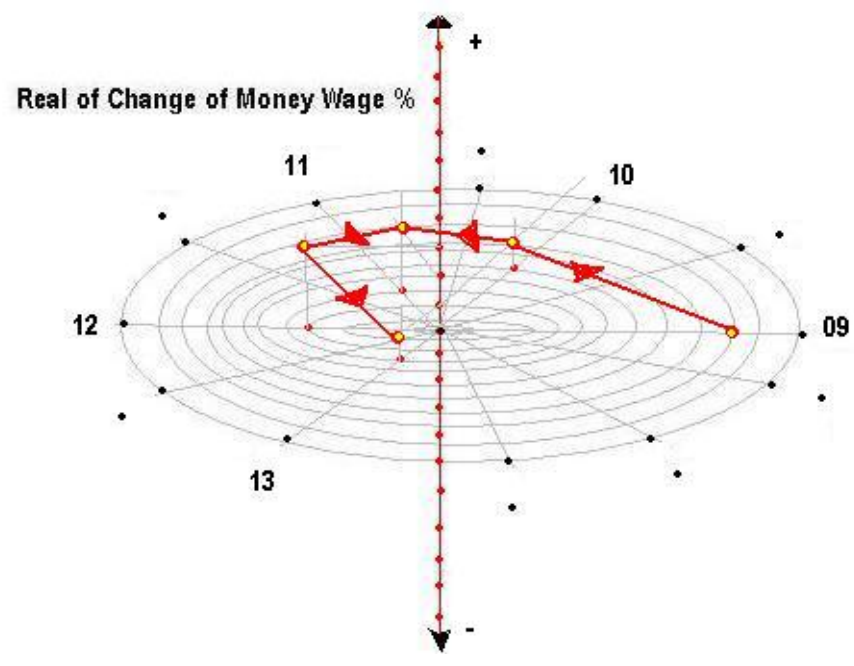

Unemployment $\%$

Figure 14. 1909-1913

Source: Adapted from "The relation between unemployment and the rate of change of money wage rates in the United Kingdom, 1861-1957", by Philips (1958) in Economica, 25(100), 283-299. 


\section{Two-Dimensional Perspective}

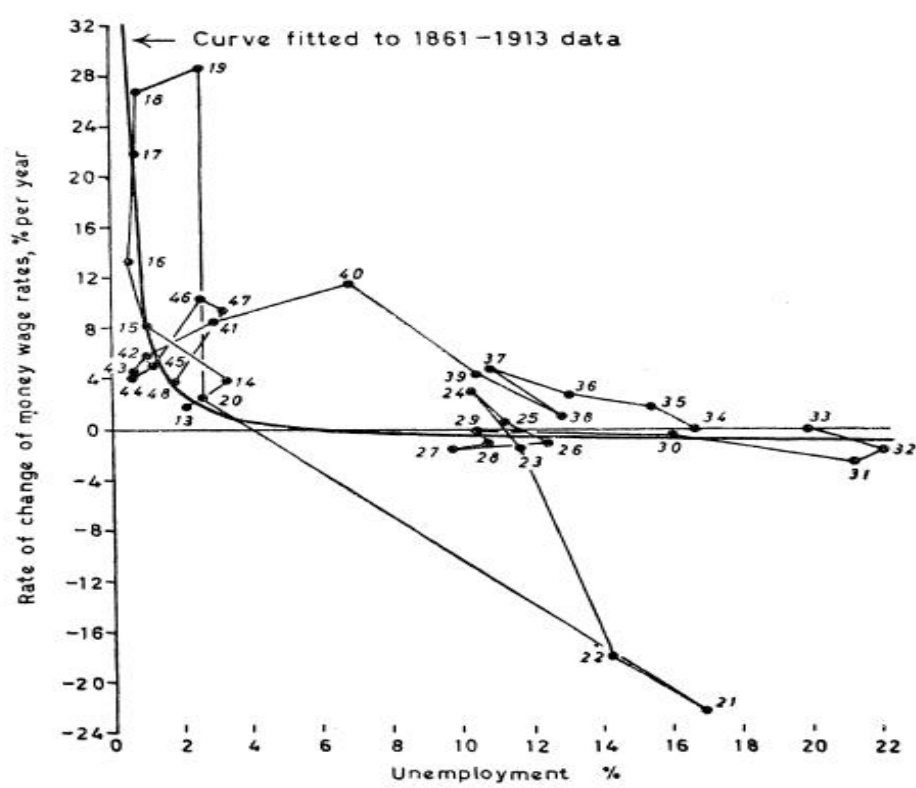

Multidimensional Perspective

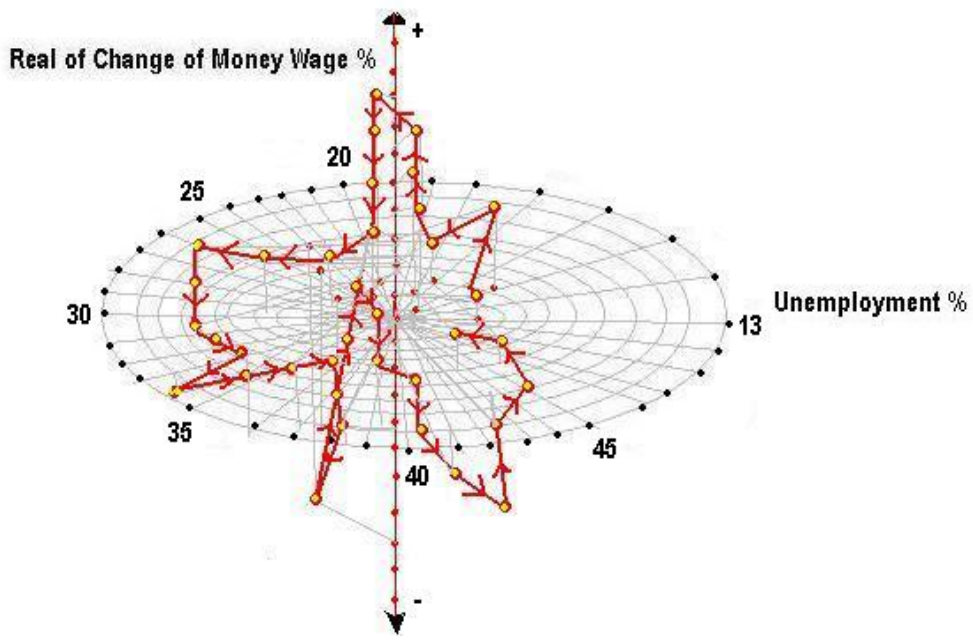

Figure 15. 1913-1948

Source: Adapted from "The relation between unemployment and the rate of change of money wage rates in the United Kingdom, 1861-1957", by Philips (1958) in Economica, 25(100), 283-299. 


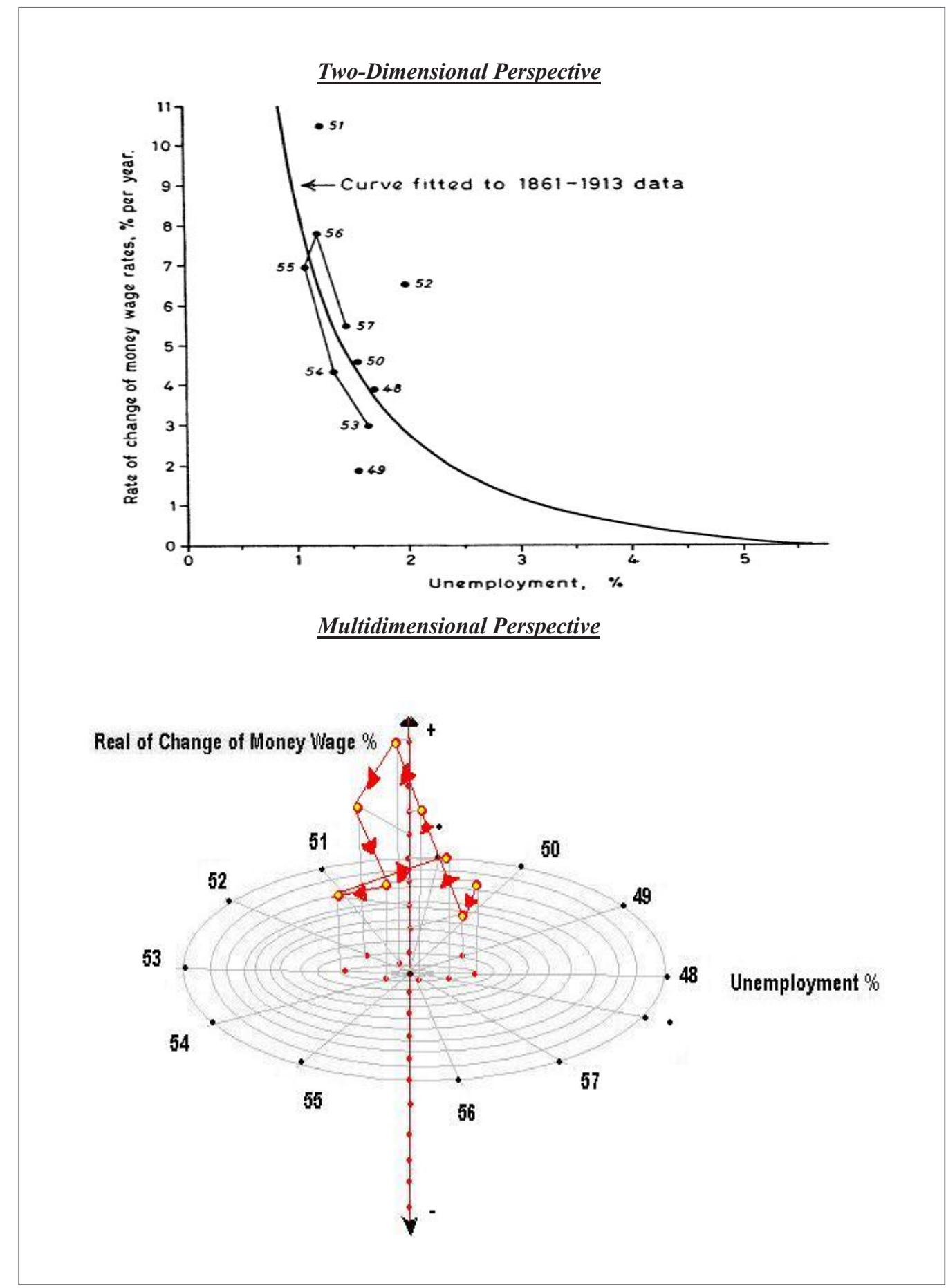

Figure 16. 1948-1957

Source: Adapted from "The relation between unemployment and the rate of change of money wage rates in the United Kingdom, 1861-1957", by Philips (1958) in Economica, 25(100), 283-299. 


\section{$\underline{\text { Two-Dimensional Perspective }}$}

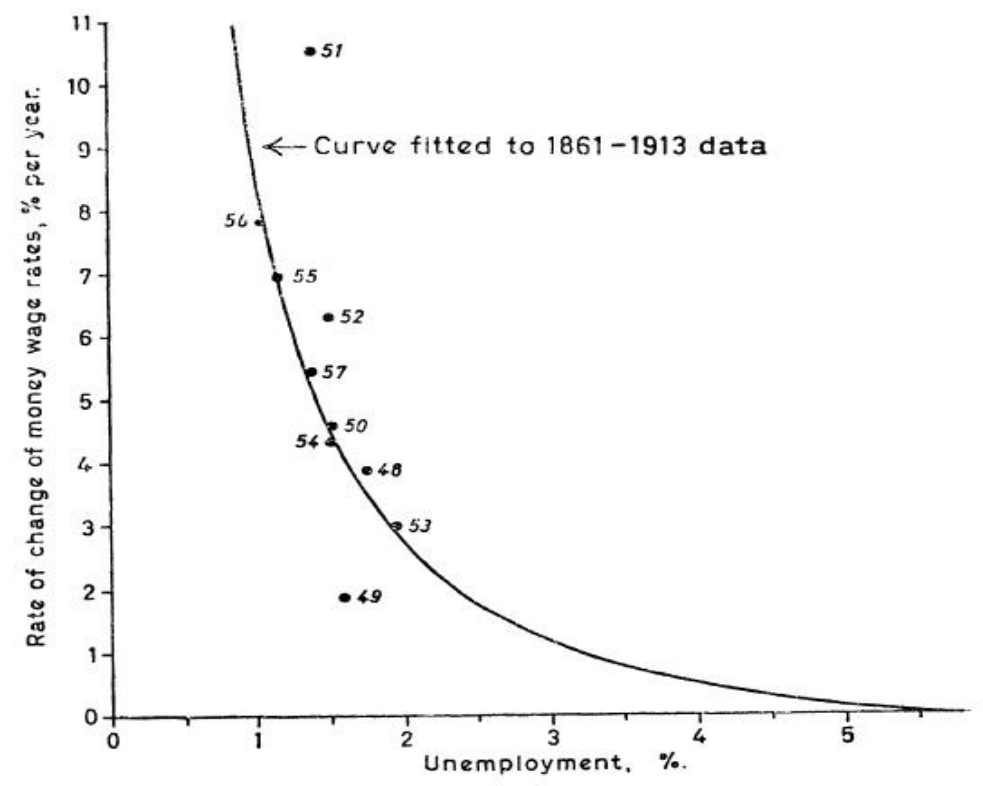

Multidimensional Perspective

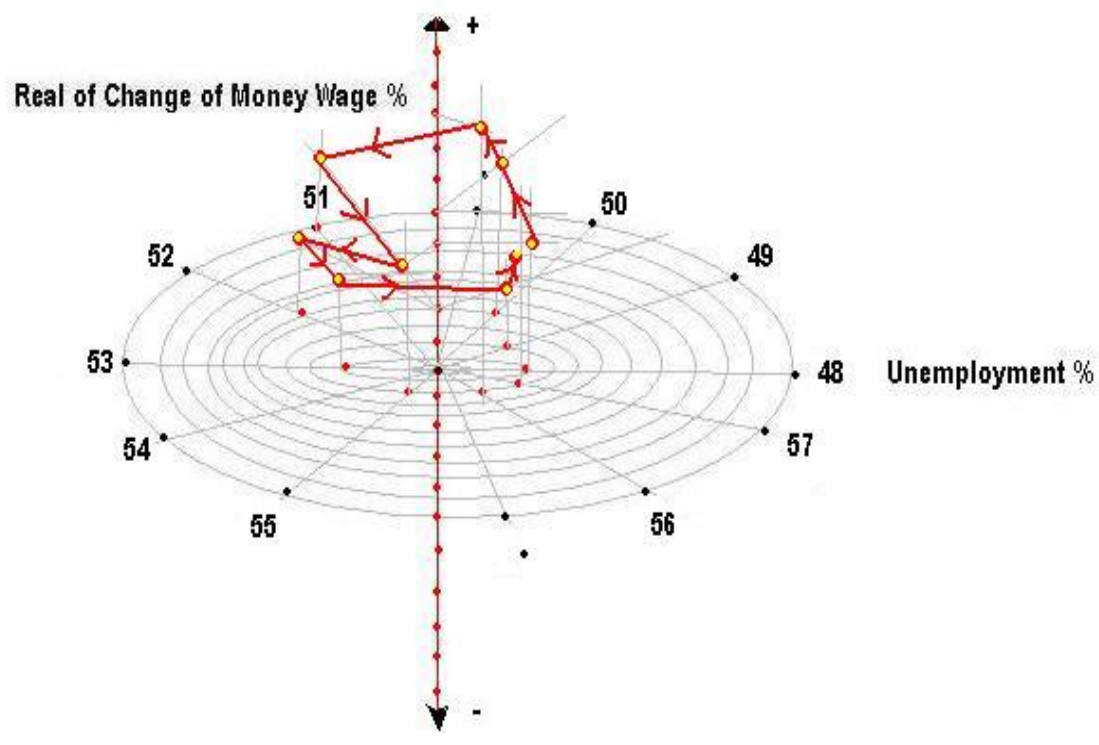

Figure 17. 1948-1957

Source: Adapted from "The relation between unemployment and the rate of change of money wage rates in the United Kingdom, 1861-1957", by Philips (1958) in Economica, 25(100), 283-299. 

graphs and performance in economics. The American Economist, 48(2), 41-52.

Friedman, M. (1968): The Role of Monetary Policy. American Economic Review, 58(1), 1-17.

Fuhrer, J. \& Moore, G. (1995). Inflation persistence. The Quarterly Journal of Economics, 110 (1), 127159.

Josifidis, K., Pucar, E. B., Srdić, S., Ivan, G. (2014). Inflation targeting in advanced vs. emerging economies before and after the crisis. Panoeconomicus, 61(1), 79-106.

Lucas, R. E., \& Sargent, T. J. (1981). Rational Expectations and Econometric Practice. Minneapolis, MN: The University of Minnesota Press.

Maas, H. (2005). William Stanley Jevons and the making of modern economics. Cambridge, UK: Cambridge University Press.

Mirowski, P. (1991). The when, the how and the why of mathematical expression in the history of economics analysis. The Journal of Economic Perspectives, 5(1), 145-157.

Pencavel, J. (2011). Real wage index numbers. The American Economic Review, 101(3), 565-570.

Phillips, A. W. (1958). The relation between unemployment and the rate of change of money wage rates in the United Kingdom, 1861-1957. Economica, 25(100), 283-299.

Playfair, W. H. (2005). Commercial and political atlas and statistical breviary. Cambridge, UK: Cambridge University Press.

Ruiz Estrada, M. A. (2011a). Multi-dimensional coordinate spaces. International Journal of Physical Sciences, 6(3), 340-357.

Ruiz Estrada, M. A. (2011b). Policy modeling: Definition, classification, and evaluation. Journal of Policy Modeling, 33(4), 523-536.

Ruiz Estrada, M. A. (2014). An introduction to the mega-dynamic disks coordinate space in vertical and horizontal position. Malaysian Journal of Sciences, 33(2), 105-109.

Wise, M. N. (2011). What (good) is historical epistemology? Erkenntnis, 75(3), 349-376. 